Please do not remove this page

RMIT

UNIVERSITY

\title{
Additive manufacturing of ultrafine-grained high-strength titanium alloys
}

Zhang, Duyao; Qiu, Dong; Gibson, Mark; Zheng, Yufeng; Fraser, Hamish; Stjohn, David; Easton, Mark https://researchrepository.rmit.edu.au/esploro/outputs/9921861044601341/filesAndLinks?institution=61 RMIT_INST\&index=null

Zhang, D., Qiu, D., Gibson, M., Zheng, Y., Fraser, H., StJohn, D., \& Easton, M. (2019). Additive manufacturing of ultrafine-grained high-strength titanium alloys. Nature, 576(7785), 91-95.

https://doi.org/10.1038/s41586-019-1783-1

Document Version: Accepted Manuscript

Published Version: https://doi.org/10.1038/s41586-019-1783-1

Repository homepage: https://researchrepository.rmit.edu.au

(C) 2019 The Author(s), under exclusive licence to Springer Nature Limited.

Downloaded On 2023/04/26 19:31:25 +1000 
Duyao Zhang, Dong Qiu, Mark A. Gibson, Yufeng Zheng, Hamish L. Fraser*, David H. StJohn, and Mark A. Easton*

\begin{abstract}
Additive manufacturing ( $\mathrm{AM}$ ), where a part is built layer-by-layer, is a promising approach for creating near-net shapes and is challenging the dominance of conventional manufacturing processes for products with high complexity and greater material efficiency ${ }^{1}$. However, achieving good mechanical properties in the as-produced part, given the variation in solidification conditions including the control of defects in $\mathrm{AM}$, is challenging. In particular there are limited opportunities for post processing to further control the microstructure/properties. Therefore, further metallurgical research on materials for $A M$ is required to accelerate the maturity of $A M$ technology for structural components. 3D-printed titanium alloys have been used in numerous applications, including the biomedical and aerospace industries. However, the 3D-printing of many conventional titanium alloys usually results in a microstructure comprised of coarse columnar grains, which often leads to undesirable anisotropic mechanical properties. In contrast to other common engineering alloys, such as aluminium, there is no commercial grain refiner, containing potent inoculants that can survive in liquid $\mathrm{Ti}$, able to control microstructure effectively. To address this challenge, we have developed a novel technique for AM by using Ti-Cu alloys with a high constitutional supercooling capacity that overrides the negative effect of a high thermal gradient in the melt pool during AM. Through this approach, it is shown that an as-printed $\mathrm{Ti}-\mathrm{Cu}$ alloy specimen is comprised of fully equiaxed, fine grained microstructure without any special process control or additional subsequent treatment. The new AM Ti-Cu alloys also display promising mechanical properties, compared to conventional alloys under similar processing conditions, due to the formation of an ultrafine eutectoid microstructure by taking full advantage of the high cooling rates and multiple thermal cycles in the AM process. We anticipate that this approach will be equally applicable to other eutectoid forming alloy systems.
\end{abstract}

\title{
Main
}

Metal based 3D printing or additive manufacturing (AM) is enabling mass customization of manufactured parts. The intrinsic high cooling rates and high thermal gradient in the metal AM process often leads to a very fine microstructure and a tendency towards almost exclusively columnar grains particularly in Ti-based alloys ${ }^{1}$. Such columnar grains in AM Ti components can cause anisotropic mechanical properties and hence are not desirable 2 . Numerous attempts to optimise the processing parameters of AM have shown that it is extremely difficult to alter the conditions such that equiaxed growth of prior $\beta$-Ti grains is promoted $^{3}$. According to the Interdependence Theory ${ }^{4}$, the key factors controlling grain 
refinement include (i) $\Delta \mathrm{T}_{\mathrm{n}}$ - critical undercooling for nucleation (inverse of particle potency), (ii) $\Delta \mathrm{T}_{\mathrm{CS}}$ - the amount of constitutional supercooling (CS) available at the front of solid/liquid interface and (iii) $\mathrm{x}_{\mathrm{sd}}$ - the average spacing between the potent nucleation particles. The $\Delta \mathrm{T}_{\mathrm{n}}$ required for nucleation needs to be obtained by $\Delta \mathrm{T}_{\mathrm{CS}}$. Therefore, a small $\Delta \mathrm{T}_{\mathrm{n}}$, a large $\Delta \mathrm{T}_{\mathrm{CS}}$ and a small $\mathrm{x}_{\text {sd }}$ will favour grain refinement. The rate of development of a CS zone is controlled by the growth restriction factor $Q$. Larger $Q$ values promote more nucleation. In metal AM, however, the melt pool dimensions coupled with a high thermal gradient significantly suppresses the extent of the CS zone making it challenging to achieve grain refinement of AM Ti alloys. Multiple research groups have explored the possibilities of adding solute elements, such as beryllium, silicon or boron to stop epitaxial growth ${ }^{5}$. However, these solute elements only decrease the width of columnar grains of AM Ti components or only achieve a partial columnar-to-equiaxed transition (CET) under AM conditions. Hence, it remains an open question whether fully equiaxed grain structures in AM Ti alloys are practically achievable through conventional grain refining paradigms.

It should be noted that in previous grain refining studies, the normalized $\mathrm{Q}$ value, i.e. $\mathrm{m}(\mathrm{k}-$ 1 ), (where $m$ is the slope of the liquidus line and $k$ is the solute partition coefficient) has been frequently used to guide the choice of solute elements. However, the solubility of a given solute element in the $\beta$-Ti phase that defines the practical maximum solute concentration, $\mathrm{c}_{0-\text { max }}$, has been neglected. By simply exploring binary $\mathrm{Ti}$ alloy phase diagrams, copper is shortlisted as one of the promising solutes with a $\mathrm{c}_{0-\text { max }}$ as high as $17 \mathrm{wt} . \%$ and a reasonably high $\mathrm{m}(\mathrm{k}-1)$ value of $6.5 \mathrm{~K}$, and this leads to an overall very high maximum $\mathrm{Q}$ value, $\mathrm{Q}_{\max }=\mathrm{c}_{0-\max } \mathrm{m}(\mathrm{k}-1)=110.5 \mathrm{~K}$, which far surpasses that of silicon or boron 6 .

In addition to the high potential for grain refining $\beta$-Ti grains, copper is also a typical eutectoid forming element in Ti binary alloy systems where $\beta \rightarrow \alpha+\mathrm{Ti}_{2} \mathrm{Cu}$ at $792^{\circ} \mathrm{C}$. Since copper diffuses rapidly in $\mathrm{Ti}$, this eutectoid reaction cannot be easily prevented from occurring even after water quenching ${ }^{7}$. Such characteristics are beneficial to the high cooling rates during an AM process and it is likely to produce a very fine eutectoid microstructure during AM improving the strength and ductility of as-printed specimens simultaneously. Therefore, in the present study, we aim to develop new AM Ti-Cu alloys (extended data Fig.1) to form fully equiaxed $\beta$-Ti grains and an ultrafine eutectoid microstructure in a one-step process.

The optical micrographs of the as-printed (see Methods) Ti-8.5Cu (in wt.\% unless otherwise specified) specimen shows fully equiaxed prior- $\beta$ grains (Fig.1b) without any noticeable cracks and with only a very small volume fraction of enclosed porosity (see extended data Fig.2). The as-printed specimen also has an excellent chemical homogeneity along the building direction (see extended data Fig.3). The prior- $\beta$ grains have a bi-modal distribution with an average grain size of $9.6 \mu \mathrm{m}$. In comparison, the microstructure of as-printed Ti-6Al$4 \mathrm{~V}$ alloy is dominated by coarse columnar grains (Fig.1a) under the same laser processing 
conditions. It can be clearly seen that the addition of copper has not only fully converted the columnar grains to equiaxed grains but also refined the prior- $\beta$ grains by two orders of magnitude. The commonly observed epitaxial growth is also completely eliminated as the grain size of the equiaxed grains is much smaller than the layer thickness of $\sim 200 \mu m$ (yellow arrows in Fig.1b). It is also worth noting that compared with other AM Ti-alloys reported thus far ${ }^{5,8-15}$, our current work has produced the smallest equiaxed prior- $\beta$ grains in 3D printed Ti alloys, as shown in Fig.1d. The extraordinary grain refining efficiency of the asprinted Ti-Cu alloys stems from the high capacity of the $\mathrm{Cu}$ solute to establish a sufficiently large CS zone in front of the solid/liquid interface (Fig.1c). In Ti-6Al-4V, the Al and V solutes provide negligible $\mathrm{CS}$ (i.e. $\mathrm{Q}=8 \mathrm{~K}$ ). In contrast, the $\mathrm{Q}$-value of the $\mathrm{Ti}-8.5 \mathrm{Cu}$ alloy is $62 \mathrm{~K}$. The actual amount of constitutional supercooling, $\Delta \mathrm{T}_{\mathrm{cs}}$, is proportional to the $\mathrm{Q}$-value ${ }^{16}$, i.e.

$\Delta \mathrm{T}_{\mathrm{CS}} \cong \mathrm{Q} * \Omega$

where $\Omega$ is a dimensionless supersaturation parameter. This means that the CS zone is 8 times greater in magnitude during AM of the Ti-8.5Cu alloy compared to Ti-6Al-4V subjected to the same laser processing condition. Sufficient CS can effectively offset the negative impact of a high thermal gradient and ensures that waves of heterogenous nucleation events can be triggered in the CS zone and a complete CET can be achieved. Based on the Interdependence theory, the grain size is also dependent on the Q-value. More Cu solute delivers higher CS faster and therefore, the size of the equiaxed prior- $\beta$ grain is reduced with increasing $\mathrm{Cu}$ content (see extended data Fig.4).

It is worth mentioning that the Scheil-Gulliver solidification path and freezing range are often used to predict the likelihood of hot tearing ${ }^{17}$. A large freezing range usually leads to less liquid being available for interdendritic feeding during the last stage of solidification. In this study, Scheil curves show a large freezing range of more than 500K (extended data Fig.5, dashed line) based on the Ti-Cu equilibrium phase diagram. However, no cracks in the as-printed Ti-Cu specimens were observed. This can be at least partially explained by Eq. (1). As the required CS for CET is usually between $10^{-1} \mathrm{~K}$ to $10 \mathrm{~K}$, the resultant supersaturation $\Omega$ is far less than 1 . This means that the heterogeneous nucleation events occur very early during solidification. The formation of fine equiaxed dendrites can effectively decrease the hot tearing susceptibility as validated in previous studies of cast alloys ${ }^{18}$.

Upon completion of $L \rightarrow \beta$ solidification, $\beta$-phase (face centred cubic structure) can decompose into different product phases in the subsequent solid-solid phase transformations subject to the cooling rate ${ }^{19}$. A high cooling rate can restrict the diffusion of atoms, which suppresses eutectoid coupled growth, resulting in martensite ( $\alpha^{\prime}$-Ti, hexagonal close packed structure) formation ${ }^{20}$. Martensite in Ti alloys can lead to higher strength but lower ductility ${ }^{8}$. As expected acicular plates of martensite (Fig.2a) were observed as a result of the high cooling rate in the single track of the AM Ti-8.5Cu alloy; however, successive layer-by-layer fabrication leads to multiple thermal cycles above and below the eutectoid reaction temperature $\left(792^{\circ} \mathrm{C}\right)$ in the previously deposited layer and thus the cooling rate of 
the $\beta$ phase decomposition decreases as the number of layers increases due to the insufficient heat dissipation (see Fig.2c). This characteristic thermal history can effectively reverse the martensitic transformation and results in ultrafine eutectoid lamellae (Fig.2b and extended data Fig.6). Similar phenomena have been observed in other compositions as well (see extended data Fig.7). Moreover, the average interlamellar spacing in the asprinted Ti-8.5Cu alloy is $46 \mathrm{~nm} \pm 7 \mathrm{~nm}$ (Fig.2b), which is significantly finer than conventionally manufactured water quenched $(\sim 150 \mathrm{~nm})$ and furnaced cooled $(\sim 1 \mu \mathrm{m})$ samples ${ }^{7}$. This is because the interlamellar spacing is controlled by the diffusion length of the $\mathrm{Cu}$ atoms, and it is significantly restricted by fast cooling.

Ti alloys, in general, have a very low thermal conductivity of $\leq 16 \mathrm{Wm}^{-1} \mathrm{~K}^{-1} 21$, which may lead to interlamellar spacing coarsening from the surface to the core due to the variation of cooling rate in a conventional normalizing heat treatment for large, bulky $\mathrm{Ti}-\mathrm{Cu}$ components. In contrast, the laser metal deposition process enables relatively constant cooling rates across the part leading to a much more uniform microstructure regardless of the size of the specimen. Only a slight increase in interlamellar spacing from the bottom $(41 \mathrm{~nm} \pm 5 \mathrm{~nm})$ to the top $(54 \mathrm{~nm} \pm 9 \mathrm{~nm})$ of the specimen was observed due to the likely decrease of cooling rates along the building direction. It is also worth mentioning that the $\mathrm{Cu}$ concentration in the eutectoid lamellae (Fig.3b-d) deviates from the equilibrium composition. The $\alpha$-Ti phase contains $2.8 \mathrm{wt} . \% \mathrm{Cu}$ and it is supersaturated as the maximum solid solubility of $\mathrm{Cu}$ in $\alpha$-Ti phase is $2.0 \mathrm{wt}$.\% at equilibrium. This indicates that a more significant precipitation hardening effect could be achieved to further increase the tensile strength through optimised post heat treatment.

Tensile tests with subsized ASTM standard specimens were performed on the as-printed alloys and the associated $0.2 \%$ offset yield strength $\left(\sigma_{y}\right)$, ultimate tensile strength (UTS) and uniform elongation $(\varepsilon)$ are summarized in Table 1. As shown in Fig.4a, comparing the Ti6.5Cu alloy and Ti-3.5Cu alloys, the eutectoid lamellae in the Ti-6.5Cu alloy increases the strength substantially but decreases the ductility. Comparing the $\mathrm{Ti}-8.5 \mathrm{Cu}$ and $\mathrm{Ti}-6.5 \mathrm{Cu}$ alloys, the Ti-8.5Cu alloy has higher strength because of the higher volume fraction of eutectoid lamellae, but lower ductility due to the hyper-eutectoid $\mathrm{Ti}_{2} \mathrm{Cu}$ particles ${ }^{22}$ (see extended data Table 1). The size of equiaxed prior- $\beta$ grains (Fig.1b and extended data Fig.4) and microstructural length-scales (Fig.2b and extended data Fig.7a-b) will likely also have an impact on the mechanical properties ${ }^{23}$. The fracture surfaces (Fig.4c-e) show changes from dimples to a typical intragranular fracture morphology, which is consistent with the change in the ductility of the alloys. Compared with conventional casting and post heat-treatment methods (Fig.4b), the mechanical properties of the as-printed Ti-Cu alloys with ultrafine equiaxed prior- $\beta$ grains and eutectoid lamellar structure display a superior combination of offset yield strength and ductility. The properties are also comparable to that of cast and wrought Ti-6Al-4V alloy ${ }^{1}$, as well as laser metal deposited Ti-6Al-4V alloy ${ }^{24}$. Furthermore, $\mathrm{Cu}$ is a relatively low-cost alloying element and $\mathrm{Ti}-\mathrm{Cu}$ alloys can be printed with mixed elementary powders rather than pre-alloyed powders. In addition, Ti-Cu alloys also have 
excellent anti-bacterial properties, good biocompatibility and corrosion resistance ${ }^{22,25-27}$. It is also anticipated that further improvements in a range of properties can be achieved through process manipulation using AM.

We have demonstrated an innovative pathway to 3D print both fine equiaxed prior- $\beta$ grains and an ultrafine eutectoid lamellar structure in Ti-Cu alloys. The experimental results validate that the solidification and subsequent eutectoid decomposition can be synergistically engineered to tailor mechanical properties to best suit specific applications. The approach to grain refinement by using alloys with high Q-values has been demonstrated across many alloying systems ${ }^{28}$ and solidification processes and has been demonstrated again here as a design methodology for Ti-alloys in additive manufacturing. The methodology is also likely to be applicable to other eutectoid systems, like pearlitic steels where the mechanical properties of these conventional alloys could be enhanced by AM for high-performance engineering applications.

\section{Methods}

Laser metal deposition Pure (99.9\%) Ti and (99.5\%) Cu spherical powders (supplied by TLS Technik GmbH \& Co and Thermo Fisher Ltd, respectively) with diameter between $50 \mu \mathrm{m}$ and $100 \mu \mathrm{m}$ (see extended data Fig.8) were blended in a Turbula shaker mixer for an hour to achieve the designed compositions. Laser metal deposition (LMD) was performed on a Trumpf TruLaser cell 7020. Before printing bulk samples, we employed single layer deposition to optimise processing parameters based on visual observations of the weld bead. The optimised LMD parameters for the studied alloys are: laser power: $800 \mathrm{~W}$, scanning speed: $800 \mathrm{~mm} / \mathrm{min}$, laser spot size: $1.5 \mathrm{~mm}$, powder flow rate: $2.0 \mathrm{RPM}$, hatch distance: $1.05 \mathrm{~mm}$, shielding gas (argon) flow: $16 \mathrm{l} / \mathrm{min}$. The processing parameters were kept the same for all Ti-xCu alloys. Three cubes of $10 \times 10 \times 10 \mathrm{~mm}^{3}$ were built on a commercially pure Ti plate with different compositions (3.5wt.\%, 6.5wt.\% and 8.5wt.\% Cu). The laser scanning route for LMD was a raster pattern with an increment of $90^{\circ}$ between each layer and the delay time between two subsequent layers was 20s. For comparison, a Ti-6Al-4V specimen was also printed using the same parameters.

For the tensile samples, three cuboids $\left(120 \times 25 \times 25 \mathrm{~mm}^{3}\right)$ were horizontally built and then machined into five tensile samples. The loading direction of tensile samples is perpendicular to the LMD building direction.

Chemical compositions The chemical composition of the as-printed samples was determined by inductively coupled plasma-atomic emission spectroscopy (ICP-AES), as summarized in extended data Table 1 . A small amount of copper evaporation is expected, as the boiling point of $\mathrm{Cu}$ is $2560^{\circ} \mathrm{C}$ which is much lower than that of $\mathrm{Ti}\left(3285^{\circ} \mathrm{C}\right)^{21}$.

X-ray micro CT The as-printed samples were scanned using X-ray micro computed tomography (GE Phoenix $V$ tome) with nominal resolution of $5 \mu \mathrm{m}$. Defect analysis including 
3D image reconstruction, relative density, dimension and percentage of the defects was performed with Volume Graphics software. The as-printed specimens are all fully dense (>99.4\%) without any lack of fusion defects. The porosity found in the as-printed specimens may come from the existing porosity in the powders (see extended data Fig.8) as well as the printing process.

X-ray diffraction Phase identification was determined by X-ray diffraction (XRD) using a Bruker AXS D4 Endeavour diffractometer over a $2 \theta$ range between $15^{\circ}$ and $90^{\circ}$ at a scanning rate of $0.06^{\circ}$ per second.

Microscopy As-printed cube samples were cut along the central-section parallel to the build direction. All the samples as well as raw powders were prepared by mounting, grinding and polishing. The samples for optical microscopy were etched by Kroll's reagent to reveal the grain boundaries. Light optical microscopy with a polarized lens was used for examination of the microstructure. Scanning electron microscopy (SEM) in backscattered electron mode (BSE) was carried out using FEI Verios 460L. Fracture tomography was analysed on a SEM in secondary electron mode.

The average grain size was measured from five optical micrographs of each alloy using the linear intercept technique. Volume fraction of lamellae phase was calculated from three BSE microstructure images (5000x magnification) by using the colour threshold.

For transmission electron microscopy (TEM) sample preparation, a FEI Scios SEM with focussed ion beam (FIB) was used to prepare site-specific TEM foils. Then, scanning transmission electron microscopy and X-ray energy dispersive spectroscopy (STEM-XEDS) mapping was performed in an image-corrected Titan3 G2 60-300 (S)TEM equipped with FEl's ChemiSTEM technology.

Solidification simulation Equilibrium and Scheil-Gulliver solidification models were simulated using Pandat software with PanTitanium database (version 2018). The $Q$ value for Ti-6Al-4V alloy and Ti-8.5Cu alloy were determined from Scheil cooling curves ${ }^{29}$.

Tensile As-printed samples were machined into rectangular tension test specimens with gauge length of $25 \mathrm{~mm}$ and thickness of $4 \mathrm{~mm}$ (Subsize specimen of ASTM standard E8/E8 M08). The tensile test loading direction is perpendicular to the LMD building direction. Quasistatic uniaxial testing was carried out at room temperature with an initial strain rate of $1.0 \times$ $10^{-3} \mathrm{~s}^{-1}$ on an MTS universal testing facility (MTS810, $100 \mathrm{kN}$ ) equipped with a non-contact laser extensometer. Five tensile specimens were tested for each composition (see extended data Fig.9). The results are then compared with ASTM standards for standard-size specimens.

\section{References}

1 Zhang, D. et al. Metal Alloys for Fusion-Based Additive Manufacturing. Advanced Engineering Materials 20, 1700952, doi:10.1002/adem.201700952 (2018). 

Materialia 87, 309-320, doi:https://doi.org/10.1016/j.actamat.2014.12.054 (2015). Herzog, D., Seyda, V., Wycisk, E. \& Emmelmann, C. Additive manufacturing of metals. Acta Materialia 117, 371-392, doi:https://doi.org/10.1016/j.actamat.2016.07.019 (2016). StJohn, D. H., Qian, M., Easton, M. A. \& Cao, P. The Interdependence Theory: The relationship between grain formation and nucleant selection. Acta Materialia 59, 49074921, doi:https://doi.org/10.1016/j.actamat.2011.04.035 (2011).

St John, D. H. et al. The Challenges Associated with the Formation of Equiaxed Grains during Additive Manufacturing of Titanium Alloys. Key Engineering Materials 770, 155-164, doi:10.4028/www.scientific.net/KEM.770.155 (2018). Bermingham, M. J., McDonald, S. D., StJohn, D. H. \& Dargusch, M. S. Beryllium as a grain refiner in titanium alloys. Journal of Alloys and Compounds 481, L20-L23, doi:https://doi.org/10.1016/j.jallcom.2009.03.016 (2009).

7 Cardoso, F. F. et al. Hexagonal martensite decomposition and phase precipitation in Ti-Cu alloys. Materials \& Design 32, 4608-4613, doi:https://doi.org/10.1016/j.matdes.2011.03.040 (2011).

Xu, W., Lui, E. W., Pateras, A., Qian, M. \& Brandt, M. In situ tailoring microstructure in additively manufactured Ti-6Al-4V for superior mechanical performance. Acta Materialia 125, 390-400, doi:https://doi.org/10.1016/j.actamat.2016.12.027 (2017).

Mitzner, S., Liu, S., Domack, M. S. \& Hafley, R. A. in 23rd Solid Freeform Fabrication Symposium. 536-555, (2012)

Wang, F., Williams, S. \& Rush, M. Morphology investigation on direct current pulsed gas tungsten arc welded additive layer manufactured Ti6Al4V alloy. The International Journal of Advanced Manufacturing Technology 57, 597-603, doi:10.1007/s00170-011-3299-1 (2011). Mereddy, S. et al. Trace Carbon Addition to Refine Microstructure and Enhance Properties of Additive-Manufactured Ti-6AI-4V. JOM 70, 1670-1676, doi:10.1007/s11837-018-2994-x (2018).

12 Wang, J. et al. Grain morphology evolution and texture characterization of wire and arc additive manufactured Ti-6Al-4V. Journal of Alloys and Compounds 768, 97-113, doi:https://doi.org/10.1016/j.jallcom.2018.07.235 (2018).

$13 \mathrm{Li}, \mathrm{Z}$., Li, J., Zhu, Y., Tian, X. \& Wang, H. Variant selection in laser melting deposited $\alpha+\beta$ titanium alloy. Journal of Alloys and Compounds 661, 126-135, doi:https://doi.org/10.1016/j.jallcom.2015.11.172 (2016).

14 Zhu, Y.-Y., Tang, H.-B., Li, Z., Xu, C. \& He, B. Solidification behavior and grain morphology of laser additive manufacturing titanium alloys. Journal of Alloys and Compounds 777, 712-716, doi:https://doi.org/10.1016/j.jallcom.2018.11.055 (2019).

15 Zhu, Y., Liu, D., Tian, X., Tang, H. \& Wang, H. Characterization of microstructure and mechanical properties of laser melting deposited Ti-6.5Al-3.5Mo-1.5Zr-0.3Si titanium alloy. Materials \& Design (1980-2015) 56, 445-453, doi:https://doi.org/10.1016/j.matdes.2013.11.044 (2014).

16 Kurz, W. \& Fisher, D. J. Fundamentals of solidification. 241 (trans tech publications Aedermannsdorf, Switzerland, 1989).

17 Fulcher, B. A., Leigh, D. K. \& Watt, T. J. Comparison of AlSi10Mg and Al 6061 processed through DMLS. in Proceedings of the Solid Freeform Fabrication (SFF) Symposium, Austin, TX, USA.46 (2014)

18 Easton, M., Wang, H., Grandfield, J., St John, D. \& Sweet, E. An analysis of the effect of grain refinement on the hot tearing of aluminium alloys. Materials forum 28, 224-229. (2004) Souza, S. A., Afonso, C. R. M., Ferrandini, P. L., Coelho, A. A. \& Caram, R. Effect of cooling rate on Ti-Cu eutectoid alloy microstructure. Materials Science and Engineering: C 29, 10231028, doi:https://doi.org/10.1016/j.msec.2008.09.007 (2009). 

martensite. Metallurgical Transactions 1, 2265-2270, doi:10.1007/BF02643444 (1970).

21 Brandes, E.A. \& Brook, G.B. Smithells Metals Reference Book, 7th Ed. (ButterworthHeinemann, Hartnolls, Bodmin, UK, 1992)

22 Zhang, E., Wang, X., Chen, M. \& Hou, B. Effect of the existing form of Cu element on the mechanical properties, bio-corrosion and antibacterial properties of Ti-Cu alloys for biomedical application. Materials Science and Engineering: C 69, 1210-1221, doi:https://doi.org/10.1016/j.msec.2016.08.033 (2016).

23 Ren, Y. M. et al. Microstructure and deformation behavior of Ti-6Al-4V alloy by high-power laser solid forming. Acta Materialia 132, 82-95, doi:https://doi.org/10.1016/j.actamat.2017.04.026 (2017).

24 Kok, Y. et al. Anisotropy and heterogeneity of microstructure and mechanical properties in metal additive manufacturing: A critical review. Materials \& Design 139, 565-586, doi:https://doi.org/10.1016/j.matdes.2017.11.021 (2018).

25 Hayama, A. O. F. et al. Effects of composition and heat treatment on the mechanical behavior of Ti-Cu alloys. Materials \& Design 55, 1006-1013, doi:https://doi.org/10.1016/j.matdes.2013.10.050 (2014).

26 Kikuchi, M. et al. Mechanical properties and microstructures of cast Ti-Cu alloys. Dental Materials 19, 174-181, doi:https://doi.org/10.1016/S0109-5641(02)00027-1 (2003).

27 Liu, R. et al. Antibacterial effect of copper-bearing titanium alloy (Ti-Cu) against Streptococcus mutans and Porphyromonas gingivalis. Scientific Reports 6, 29985, doi:10.1038/srep29985 (2016).

28 Easton, M. A., Qian, M., Prasad, A. \& StJohn, D. H. Recent advances in grain refinement of light metals and alloys. Current Opinion in Solid State and Materials Science 20, 13-24, doi:https://doi.org/10.1016/j.cossms.2015.10.001 (2016).

29 Schmid-Fetzer, R. \& Kozlov, A. Thermodynamic aspects of grain growth restriction in multicomponent alloy solidification. Acta Materialia 59, 6133-6144, doi:https://doi.org/10.1016/j.actamat.2011.06.026 (2011). Okamoto, H. Phase diagrams for binary alloys. ASM International 44 (2010).

\section{Acknowledgements}

The authors would like to acknowledge the Australian Research Council (ARC) for the financial support [grant number DP160100560]. The authors would like to thank Prof Milan Brandt and Mr Alan Jones for their support during LMD manufacturing, Dr Kun Yang for her support for etching AM Ti samples and Dr Edward Lui for his support for tensile testing. The authors wish to acknowledge the facilities, and the scientific and technical assistance, of the the RMIT Microscopy \& Microanalysis Facility (RMMF). The authors also wish to acknowledge the Center for Electron Microscopy and Analysis (CEMAS) at the Ohio State University for providing access to research facilities.

\section{Author information}

These authors contributed equally: Duyao Zhang, Dong Qiu

\section{Affiliations}

Centre for Additive Manufacturing, School of Engineering, RMIT University, Melbourne VIC 3001, Australia, 
Duyao Zhang, Dong Qiu, Mark A. Gibson \& Mark A. Easton

Center for the Accelerated Maturation of Materials, Department of Materials Science and Engineering, The Ohio State University, Columbus Ohio 43212, USA

Yufeng Zheng \& Hamish L. Fraser

The Commonwealth Scientific and Industrial Research Organisation (CSIRO) Manufacturing, Clayton, VIC 3168, Australia

Mark A. Gibson

School of Mechanical and Mining Engineering, University of Queensland, St Lucia, QLD 4072, Australia

David H. StJohn

Note: Y.Z current address: Department of Chemical and Materials Engineering, University of Nevada Reno, Reno, NV 89557, USA

\section{Contributions}

M.A.E., M.A.G., D.H.S.J. and H.L.F. conceived the idea. D.Q. and D.Z. designed the experiments. D.Z. and D.Q. were involved with processing parameter development and sample print; and performed the microstructure characterization. Y.Z. and D.Z. conducted the transmission electron microscopy and analysed the results. D.Z. performed mechanical testing, simulations and X-Ray CT. M.A.E. supervised the project. D.Z. and D.Q. drafted the manuscript. All authors discussed the results and edited the manuscript at all stages.

\section{Competing interests}

The authors declare no competing financial interests.

\section{Corresponding author}

Correspondence to Mark. A. Easton and Hamish. L. Fraser

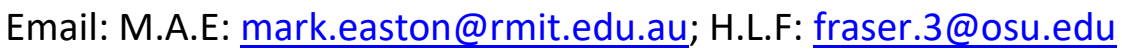

\section{Data Availability Statement}

The datasets generated during and/or analysed during the current study are available from the corresponding author on reasonable request. 


\section{Main figures and table Legends}

Figure 1: 3D printing of Ti-6Al-4V and Ti-8.5Cu alloys. a Optical graph of an as-printed Ti$6 \mathrm{Al}-4 \mathrm{~V}$ alloy showing coarse columnar grains. In contrast, $\mathbf{b}$ optical microstructures of an asprinted Ti-8.5Cu alloy show fine, fully equiaxed grains along the building direction under the same printing conditions. The yellow arrows in $\mathbf{b}$ indicate successive layer boundaries approximately every $200 \mu \mathrm{m}$ and the average prior- $\beta$ grain size is $9.6 \mu \mathrm{m}$ measured by the linear intercept technique. The inset in $\mathbf{b}$ shows an enlarged portion of a local region with ultrafine grains. c Schematic diagram of the grain growth mechanism of Ti-8.5Cu and Ti-6Al$4 \mathrm{~V}$ alloys. $\mathrm{T}_{\mathrm{A}}$ is the profile of the actual temperature of the melt, $\mathrm{T}_{\mathrm{E}}$ is the profile of the equilibrium liquidus temperature. The values of $\Delta \mathrm{T}_{\mathrm{cs}}\left(=\mathrm{T}_{\mathrm{E}}-\mathrm{T}_{\mathrm{A}}\right)$ and $\Delta \mathrm{T}_{\mathrm{n}}$ is qualitatively represented by the length bars. For the Ti-8.5Cu alloy, a CS zone ahead of the solid-liquid interface is formed because of the solute $\mathrm{Cu}$ which is segregated around the first $\beta-\mathrm{Ti}$ dendritic grain. However, for the Ti-6AI-4V alloy, solute Al and $\mathrm{V}$ contribute negligible $\Delta \mathrm{T}_{\mathrm{cs}}$, which is far less than the nucleation undercooling $\Delta \mathrm{T}_{\mathrm{n}}$ during solidification. As a result, wide columnar grains with an average width of $120 \mu \mathrm{m}$ grow in the Ti-6Al-4V alloy but fine equiaxed grains grow in the Ti-8.5Cu alloy. $\mathbf{d}$ Summary of the area percentage of equiaxed grains versus grain size for the as-printed Ti-alloys ${ }^{5,8-14}$. Ti-Si alloys include Ti-0.04, 0.19 and 0.75Si, respectively. Other Ti alloys include Ti-6Al-2Zr-2Sn-3Mo-1Cr-2Nb and Ti-3Al-10V-2Fe. Most as-printed Ti-alloys have either fully columnar or a mixed columnar and equiaxed prior- $\beta$ grains and the grain sizes are in the range of $100 \mu \mathrm{m}$ to $1 \mathrm{~mm}$. This work shows that fully equiaxed prior- $\beta$ grains can be achieved throughout the as-printed samples. Error bars represent one standard deviation.

Figure 2: SEM characterization of Ti-8.5Cu alloy presented in Fig.1b. a-b BSE images of the as-printed Ti-8.5Cu alloy showing the microstructure evolution at the first layer (indicated by the red spots) during the 3D printing process. a The martensite phase forms when only a single layer was deposited and $\mathbf{b}$ fine eutectoid lamellae surrounded by hyper-eutectoid $\mathrm{Ti}_{2} \mathrm{Cu}$ particles form when multiple layers were deposited. The processing parameters were constant. c A schematic continuous cooling transformation diagram illustrates different solid-solid phase transformation pathways for laser deposition of the first layer and the successive multiple layers. Heat accumulates during the deposition of successive layers thus the cooling rate is reduced and therefore the $\beta \rightarrow \alpha+\mathrm{Ti}_{2} \mathrm{Cu}$ reaction is complete before the martensite transformation temperature $\left(\mathrm{M}_{\mathrm{s}}\right)$ is reached.

Figure 3: TEM characterization of as-printed Ti-8.5Cu alloy. a bright-field image showing the ultra-fine eutectoid lamellar structure and a small portion of hyper-eutectoid $\mathrm{Ti}_{2} \mathrm{Cu}$ particles close to the prior- $\beta$ grain boundaries. $\mathbf{b}$ - $\mathbf{d}$ X-ray energy dispersive spectroscopy (XEDS) mapping on a section of the eutectoid lamellar structure, $\mathbf{b}$ bright-field image, $\mathbf{c ~ T i}$ elemental map and $\mathbf{d}$ Cu elemental map. XEDS point analyses show that the $\mathrm{Cu}$ contents in the lamellar structure are $2.8 \mathrm{wt} . \%$ in the $\alpha$-Ti phase and $39.1 \mathrm{wt} . \%$ in the $\mathrm{Ti}_{2} \mathrm{Cu}$ phase. Under 
equilibrium condition, the maximum solubility of $\mathrm{Cu}$ in $\alpha-\mathrm{Ti}$ is $2.0 \mathrm{wt} . \%$ and $\mathrm{Cu}$ in $\mathrm{Ti}_{2} \mathrm{Cu}$ phase is $39.9 w t . \%{ }^{21}$.

Figure 4: Mechanical properties of as-printed Ti-Cu alloys. a Representative engineering stress-strain curves of the as-printed materials in this study; error bars represent one standard deviation. $\mathbf{b}$ Yield strength $(0.2 \%$ offset) versus tensile elongation to failure for Ti$\mathrm{Cu}$ alloys manufactured by different methods; these alloys are also comparable with that of the ASTM standard for a Ti-6Al-4V alloy. c Ductile fracture surface of Ti-3.5Cu showing small dimples. $\mathbf{d}$ Fracture surface of Ti-6.5Cu showing a mixture of regions of small dimples with regions of cleavage facets. e Brittle fracture surface of Ti-8.5Cu showing only cleavage facets.

Table 1 Mechanical properties of as-printed Ti-Cu alloys.

\begin{tabular}{llll}
\hline Samples & $\sigma_{y}$ (MPa) & UTS (MPa) & $\varepsilon(\%)$ \\
\hline Ti-3.5Cu & $747 \pm 7$ & $867 \pm 8$ & $14.9 \pm 1.9$ \\
Ti-6.5Cu & $964 \pm 31$ & $1073 \pm 27$ & $5.5 \pm 0.4$ \\
Ti-8.5Cu & $1023 \pm 29$ & $1180 \pm 21$ & $2.1 \pm 0.6$ \\
\hline
\end{tabular}




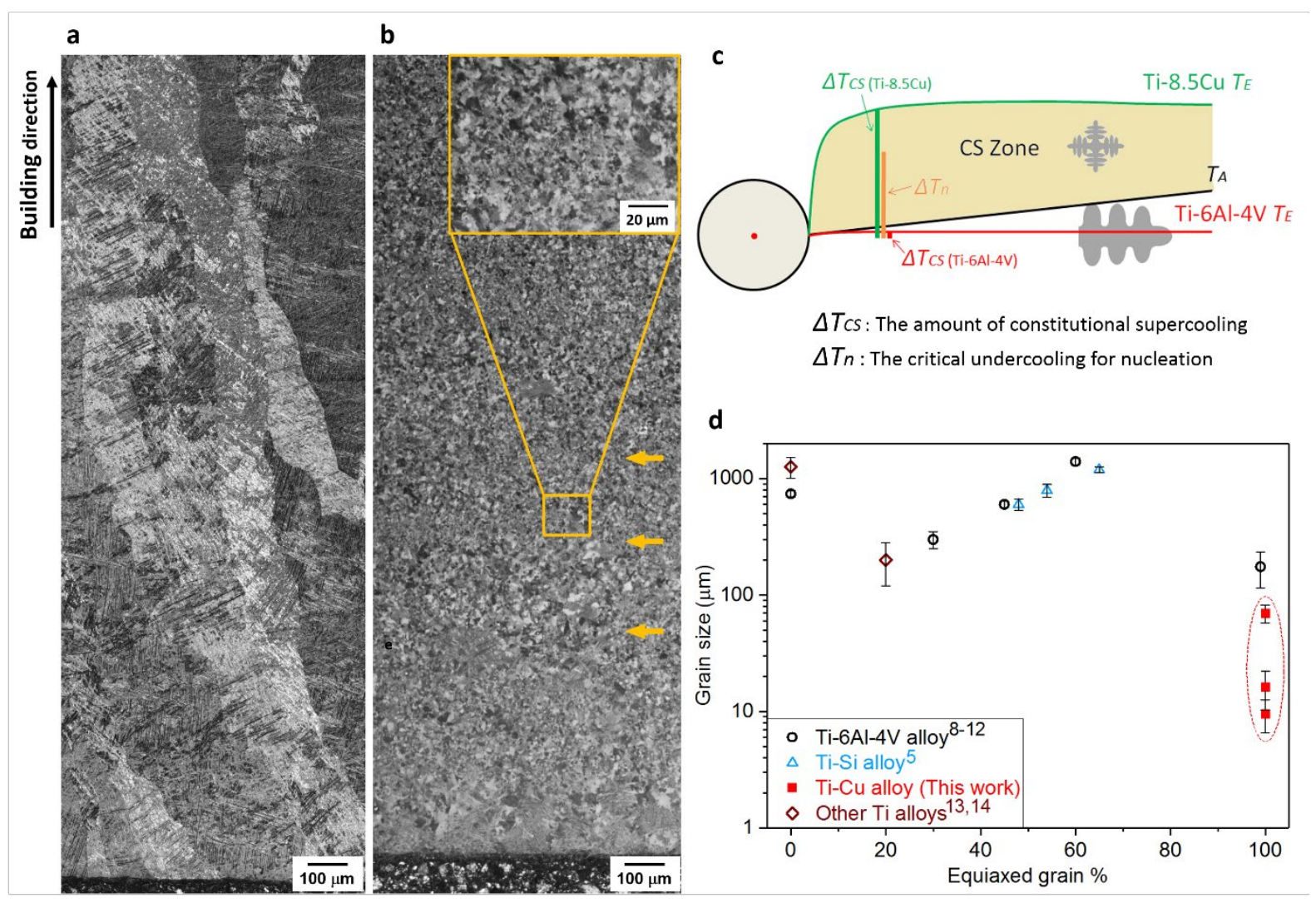

Figure 1 

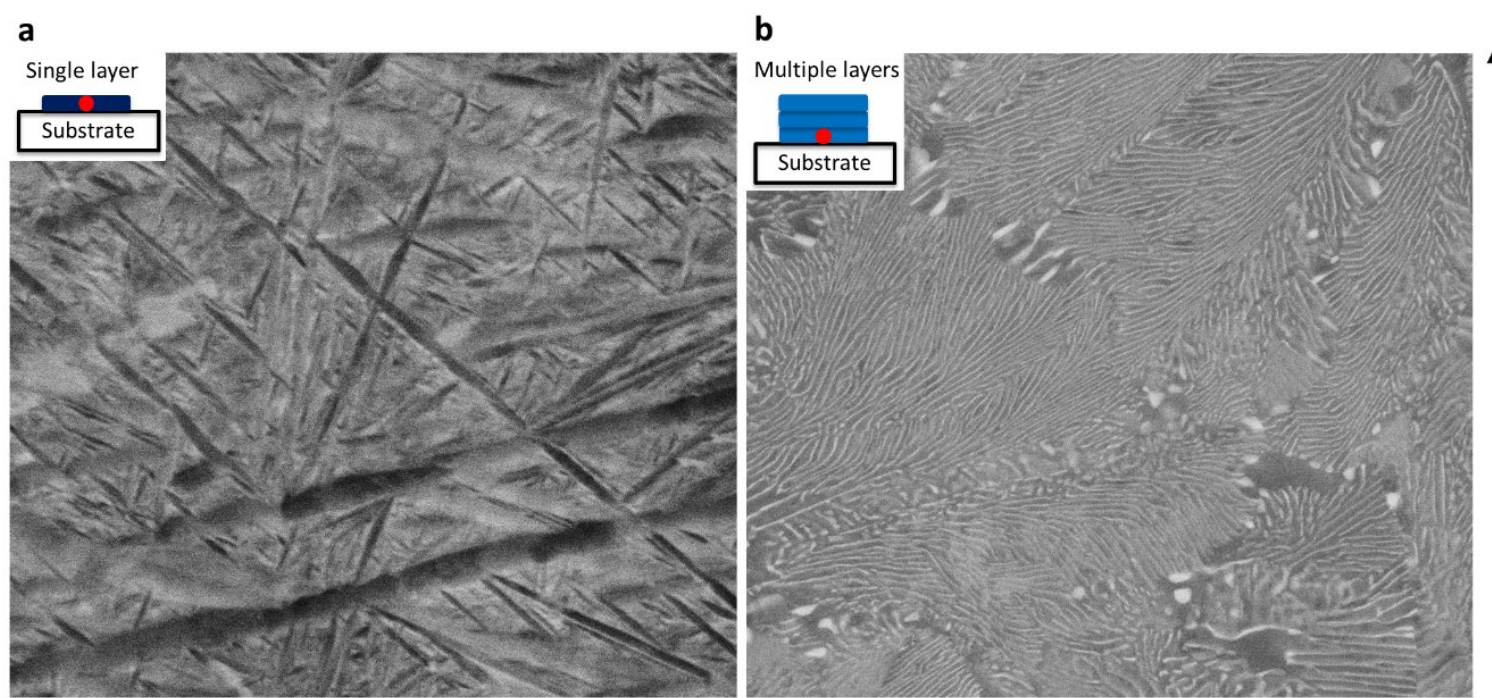

\section{罢}

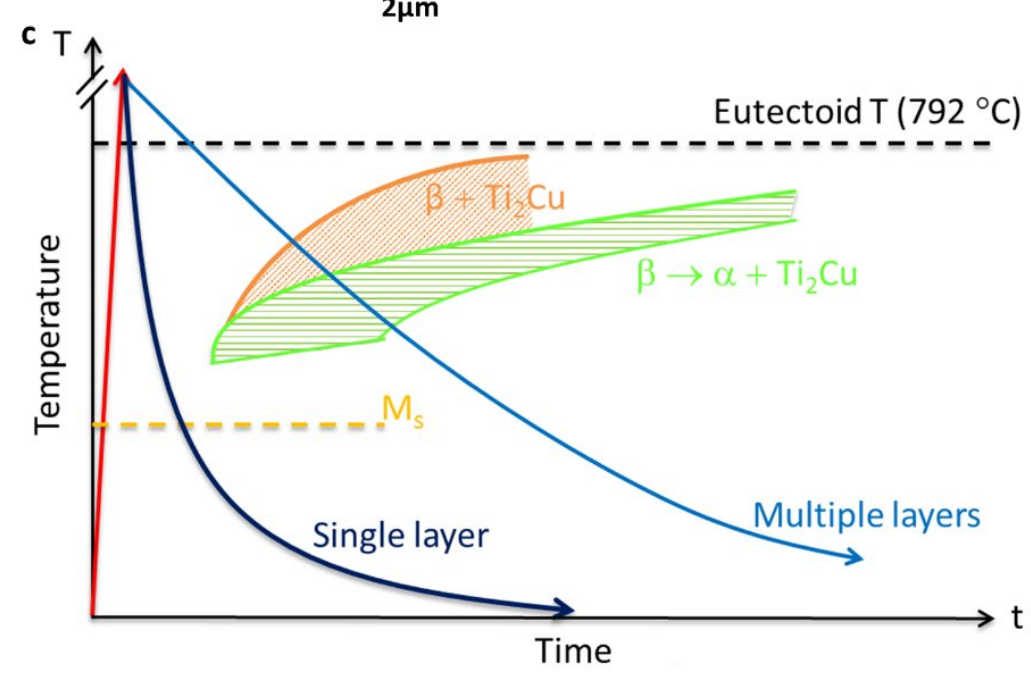

Figure 2 
a

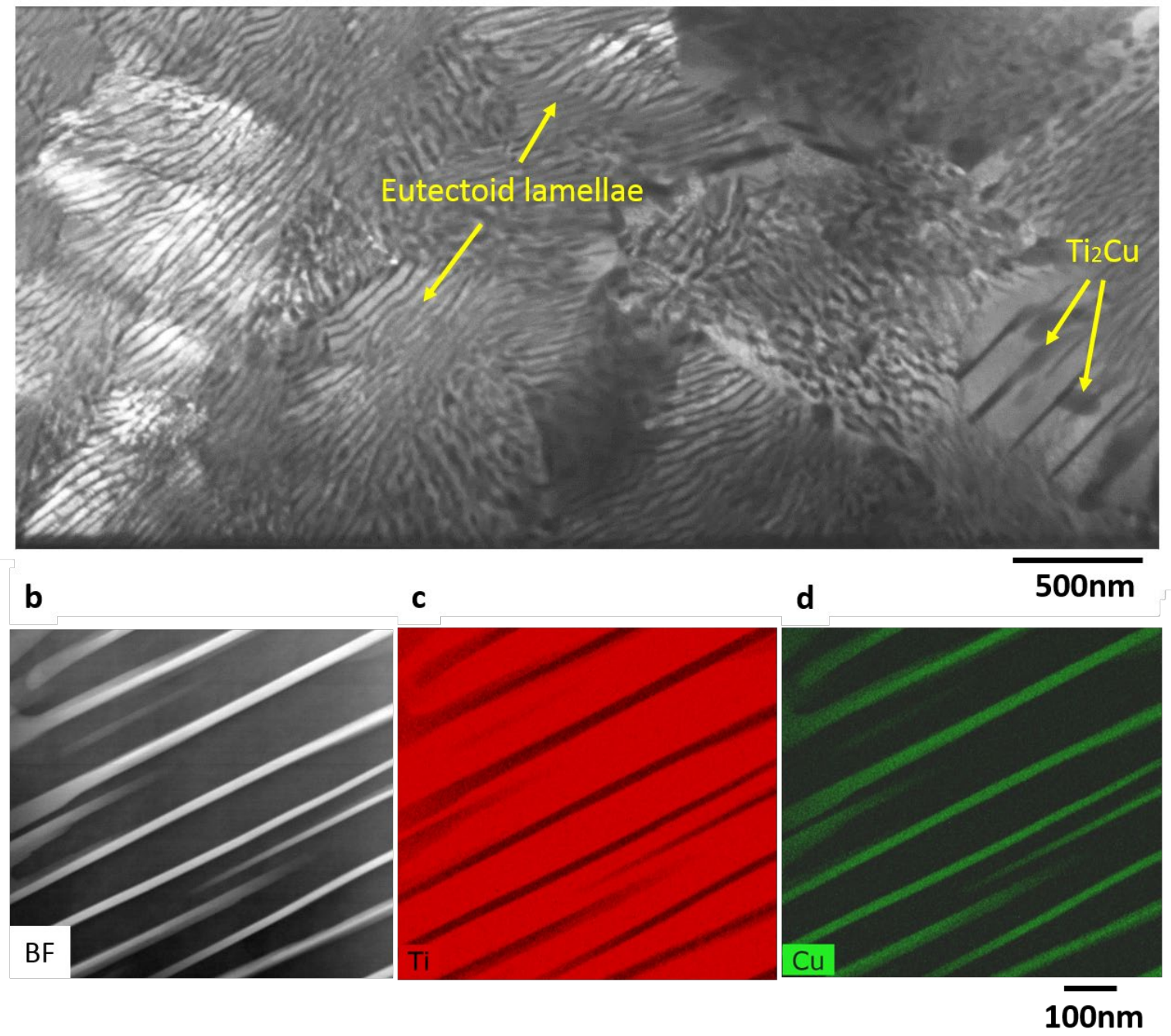

Figure 3 

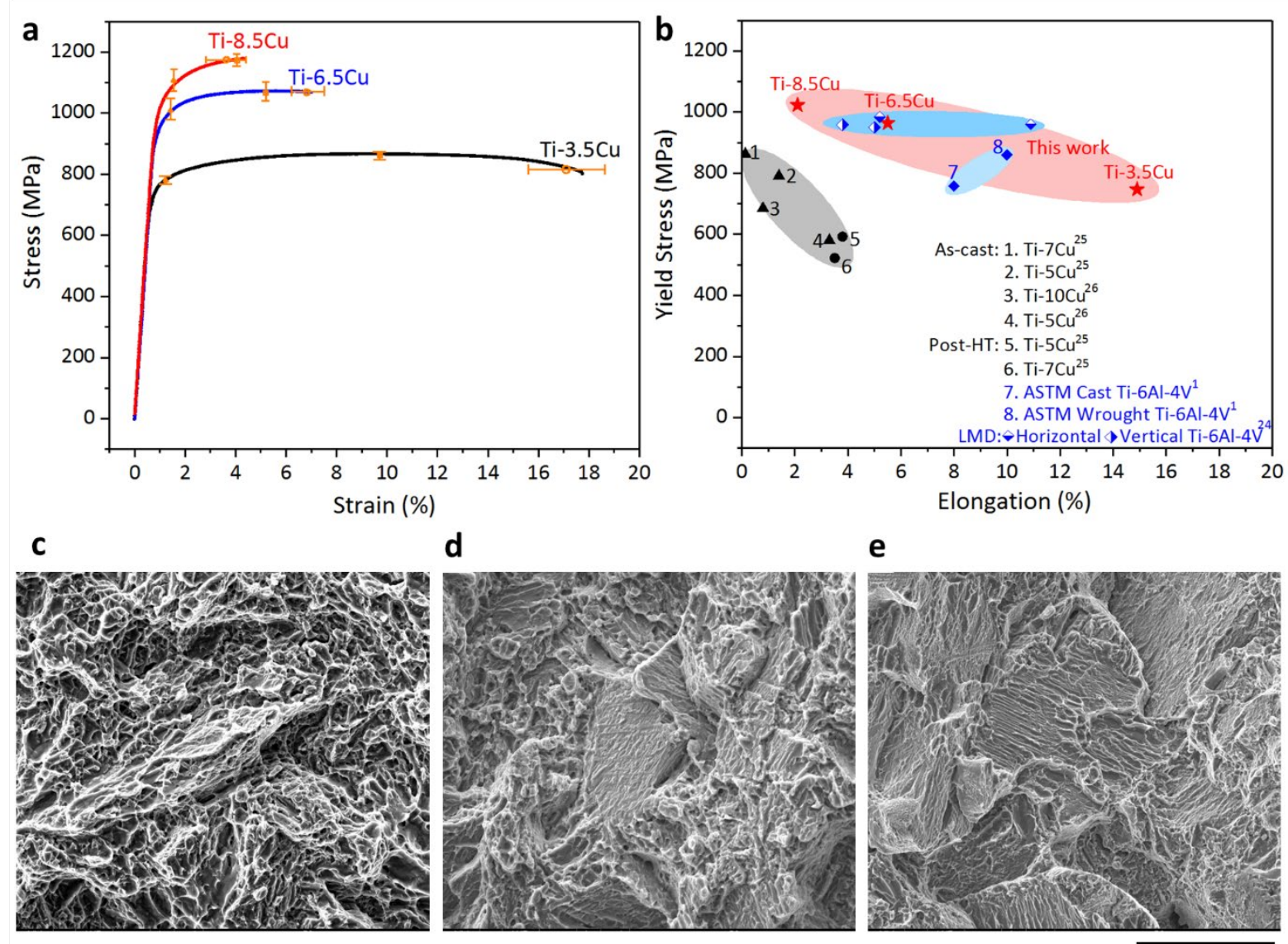

$50 \mu \mathrm{m}$

Figure 4 


\section{Extended Data Legends}

Extended Data Figure 1: Portion of the Ti-Cu phase diagram adapted from [30], indicating the compositions selected for LMD. The reason for selecting 3.5, 6.5 and $8.5 \mathrm{wt} . \%$ of $\mathrm{Cu}$ is to explore the behaviour of hypo-eutectoid, eutectoid and hyper-eutectoid compositions under AM.

Extended Data Figure 2: 3D visualization of porosity of manufactured specimens in the XYZ coordinate system, a Ti-3.5Cu b Ti-6.5Cu and $\mathbf{c ~ T i - 8 . 5 C u , ~} \mathbf{d}$ calculated relative density of asprinted specimens.

Extended Data Figure 3: XEDS results of the Cu content along the building direction for Ti$8.5 \mathrm{Cu}$ alloy (base point: $0 \mathrm{~mm}$ ) showing that the chemical composition is homogeneous.

Extended Data Figure 4: Polarized optical microstructures showing the equiaxed grains of asprinted $\mathbf{a}$ Ti-3.5Cu and $\mathbf{b}$ Ti-6.5Cu specimens. The average grain size is $69.8 \mu \mathrm{m}$ for Ti-3.5Cu and $16.3 \mu \mathrm{m}$ for $\mathrm{Ti}-6.5 \mathrm{Cu}$.

Extended Data Figure 5: Solidification curves for different Cu compositions under equilibrium and Scheil conditions. Scheil curves show a significantly enlarged temperature interval between liquidus and solidus temperatures compared with the equilibrium condition.

Extended Data Figure 6: Experimental XRD spectra collected from the as-printed Ti-8.5Cu alloy indicates that only two phases are present in the specimen: $\alpha-\mathrm{Ti}$ and $\mathrm{Ti}_{2} \mathrm{Cu}$.

Extended Data Figure 7: BSE images of as-printed specimens showing the $\mathbf{a}-\mathbf{b}$ fine $\alpha$ phases when multiple layers were deposited (images were taken at the first layer of build specimens, indicated by the red spots) and c-d, martensite phase when only a single layer was deposited.

Extended Data Figure 8: SEM image of the cross section of a titanium powder and $\mathbf{b}$ copper powder. The powders are in spherical shape with a diameter between $50 \mu \mathrm{m}$ and $100 \mu \mathrm{m}$ and porosity can be observed within some powder particles. The yellow arrows indicate examples where powder particles fell out of the resin during the polishing process.

Extended Data Figure 9: Engineering stress/strain curves of the 3D-printed materials tested in this study, indicating good repeatability.

Extended Data Table 1: Measured chemical compositions (wt.\%) and volume fraction of eutectoid lamellae in the as-printed alloys. 


\section{Extended Data Figures and Table}

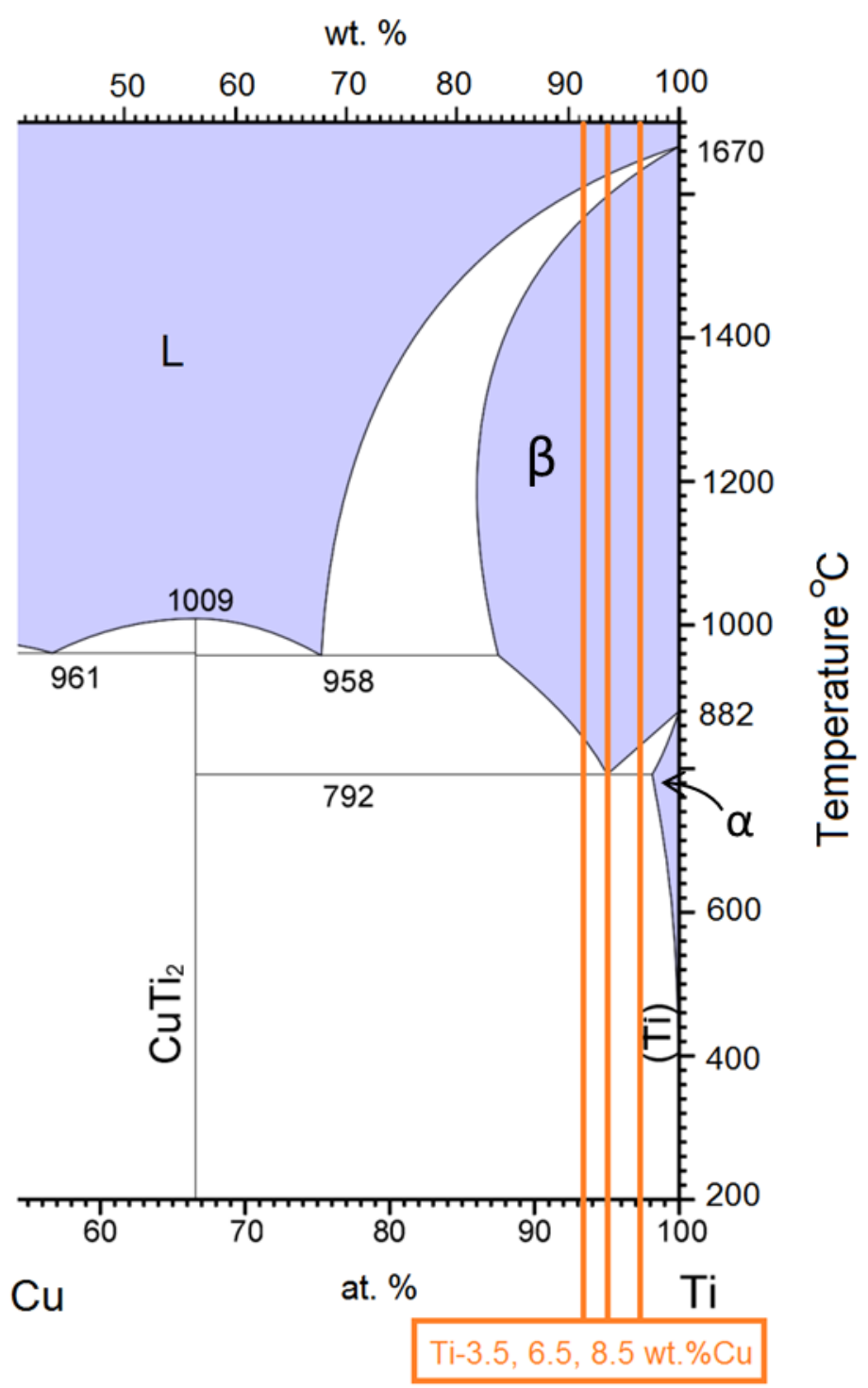

Extended Data Figure 1: Portion of the Ti-Cu phase diagram adapted from [30], indicating the compositions selected for LMD. The reason for selecting 3.5, 6.5 and $8.5 \mathrm{wt}$.\% of $\mathrm{Cu}$ is to explore the behaviour of hypo-eutectoid, eutectoid and hyper-eutectoid compositions under AM. 
a
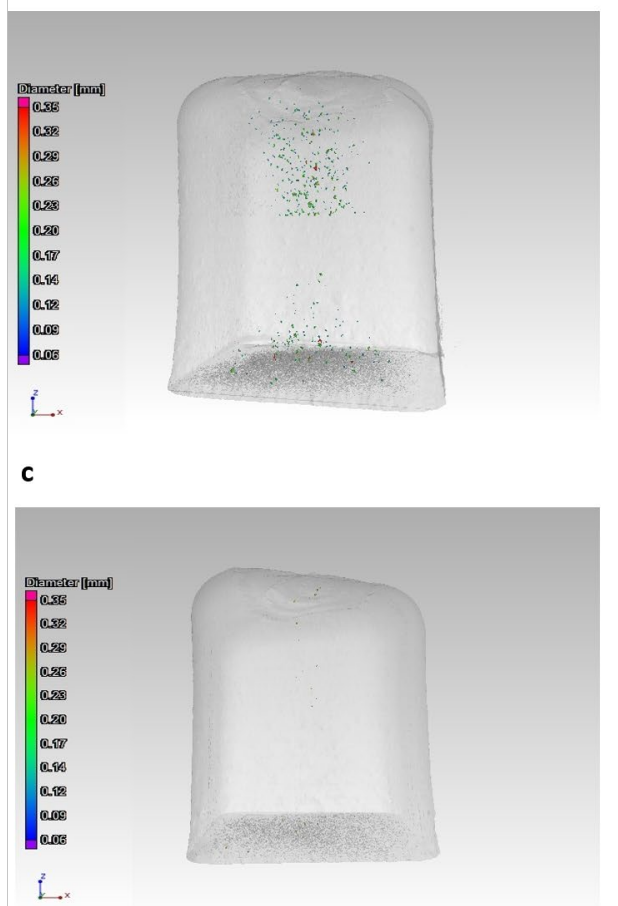

b
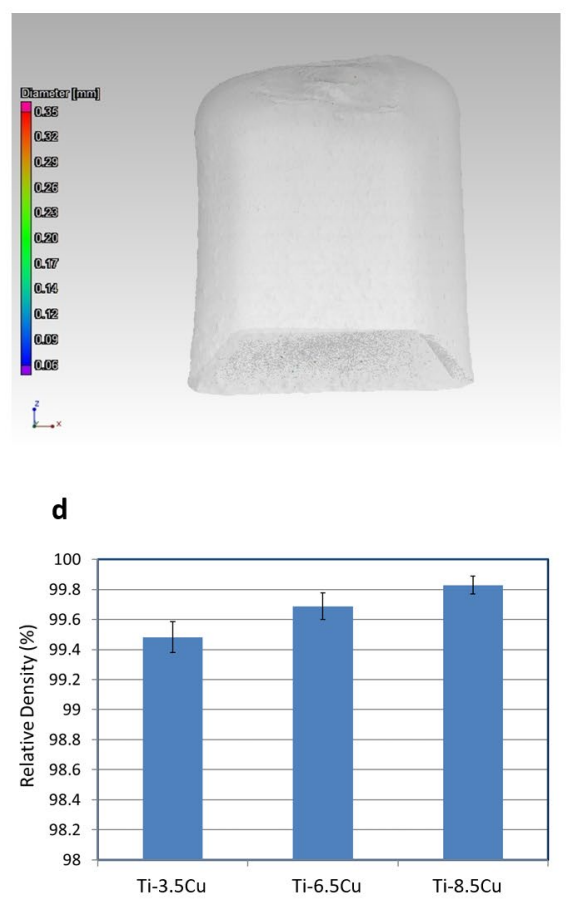

Extended Data Figure 2: 3D visualization of porosity of manufactured specimens in the $\mathrm{XYZ}$ coordinate system, a Ti-3.5Cu b Ti-6.5Cu and $\mathbf{c ~ T i - 8 . 5 C u , ~} \mathbf{d}$ calculated relative density of asprinted specimens.

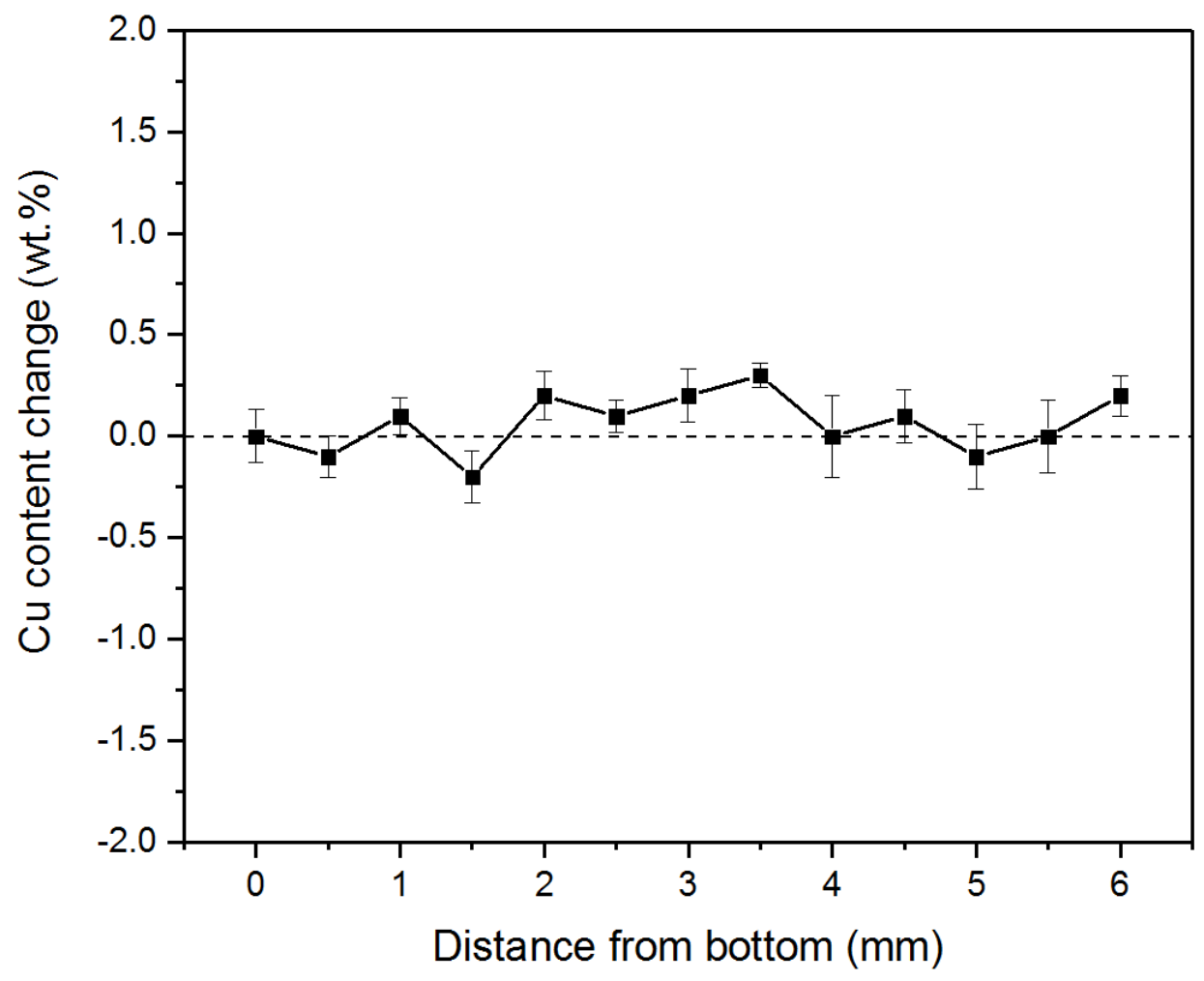

Extended Data Figure 3: XEDS results of the Cu content along the building direction for Ti$8.5 \mathrm{Cu}$ alloy (base point: $0 \mathrm{~mm}$ ) showing that the chemical composition is homogeneous. 
a

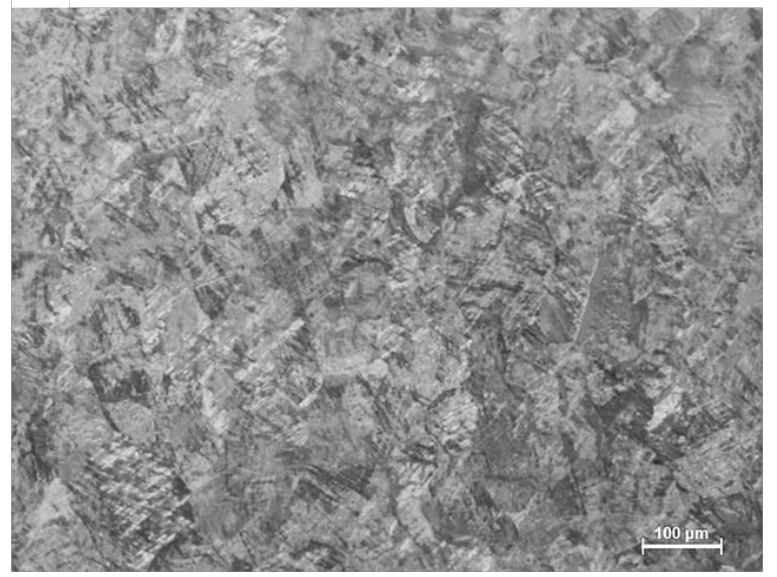

b

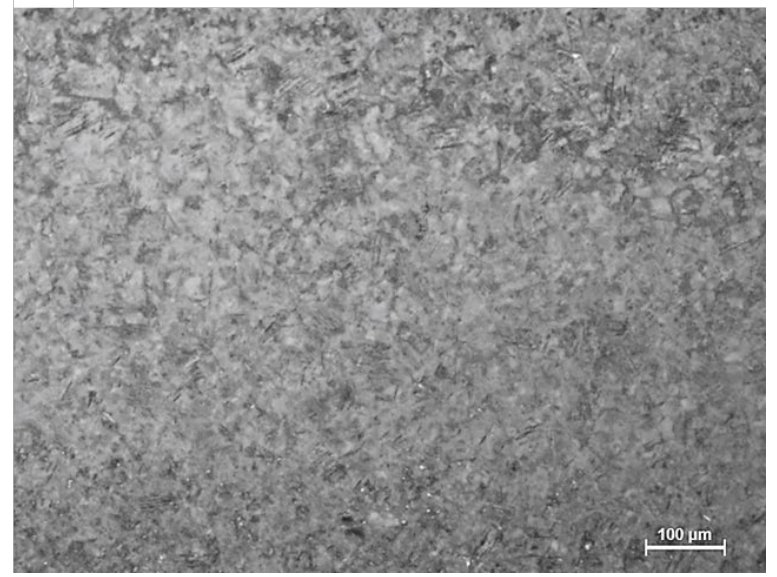

Extended Data Figure 4: Polarized optical microstructures showing the equiaxed grains of asprinted $\mathbf{a} \mathrm{Ti}-3.5 \mathrm{Cu}$ and $\mathbf{b} \mathrm{Ti}-6.5 \mathrm{Cu}$ specimens. The average grain size is $69.8 \mu \mathrm{m}$ for Ti-3.5Cu and $16.3 \mu \mathrm{m}$ for Ti-6.5Cu.

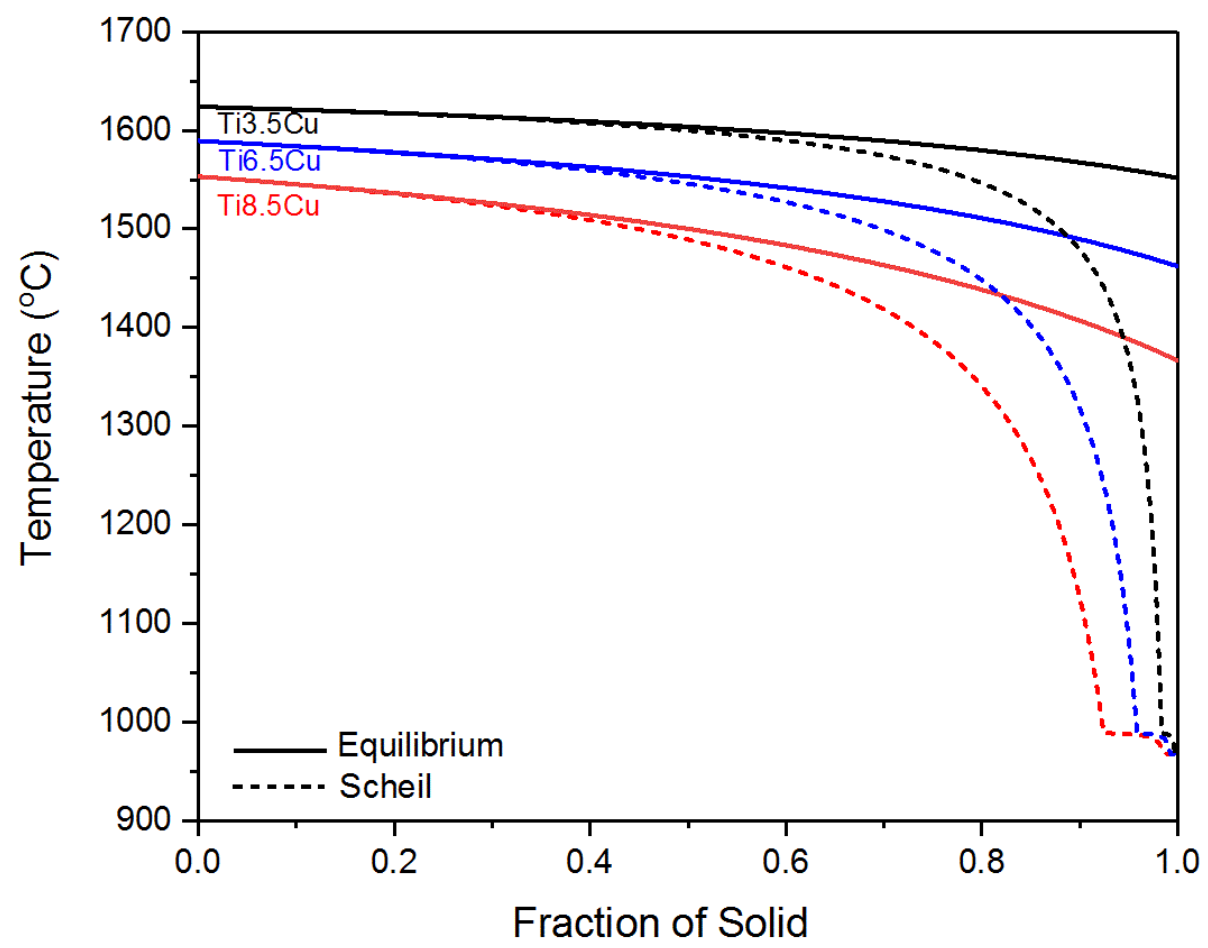

Extended Data Figure 5: Solidification curves for different $\mathrm{Cu}$ compositions under equilibrium and Scheil conditions. Scheil curves show a significantly enlarged temperature interval between liquidus and solidus temperatures compared with the equilibrium condition. 


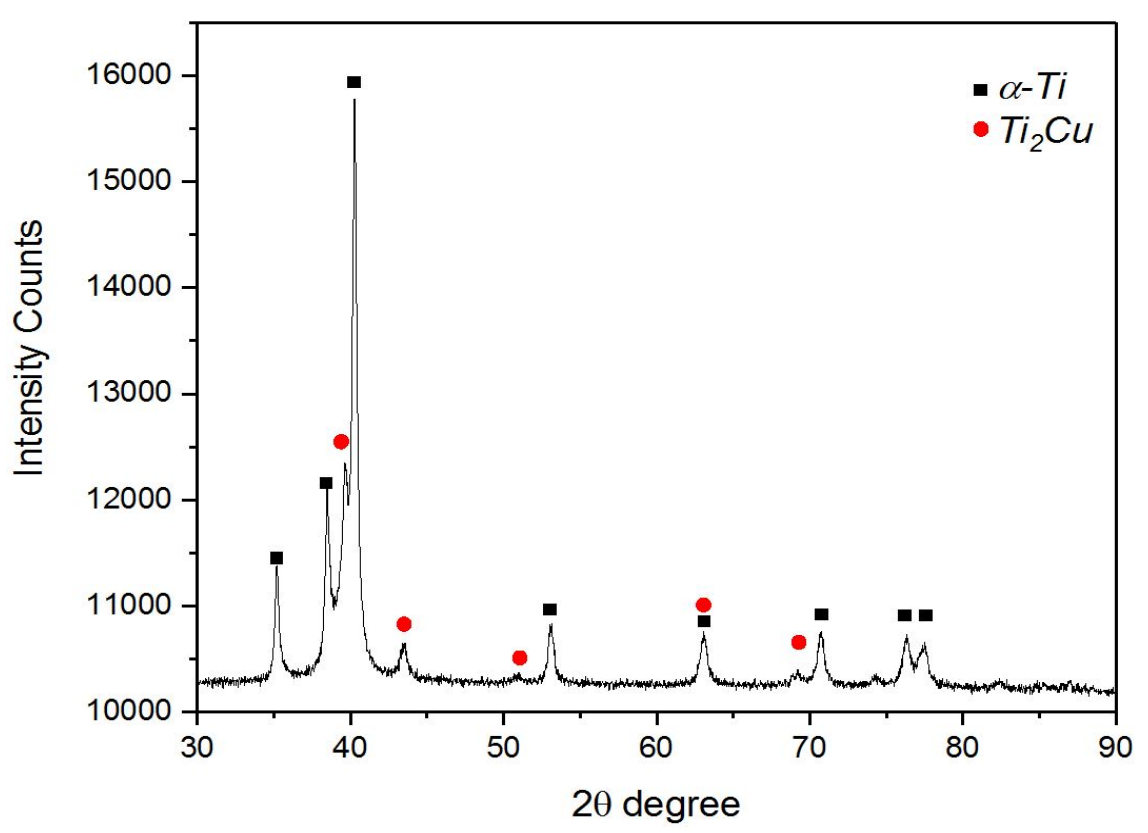

Extended Data Figure 6: Experimental XRD spectra collected from the as-printed Ti-8.5Cu alloy indicates that only two phases are present in the specimen: $\alpha-\mathrm{Ti}$ and $\mathrm{Ti}_{2} \mathrm{Cu}$.

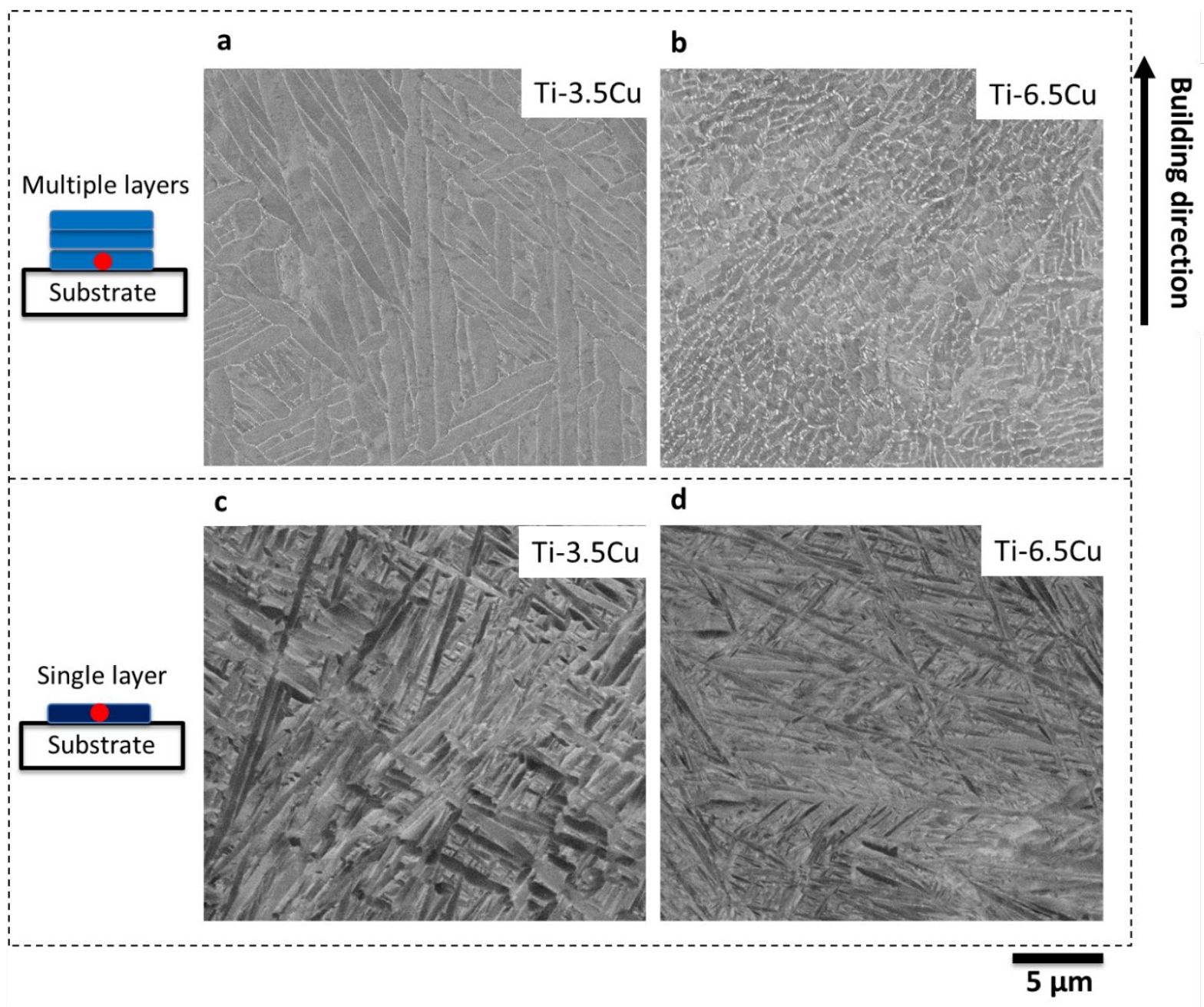


Extended Data Figure 7: BSE images of as-printed specimens showing the $\mathbf{a}-\mathbf{b}$ fine $\alpha$ phases when multiple layers were deposited (images were taken at the first layer of build specimens, indicated by the red spots) and c-d, martensite phase when only a single layer was deposited.

a

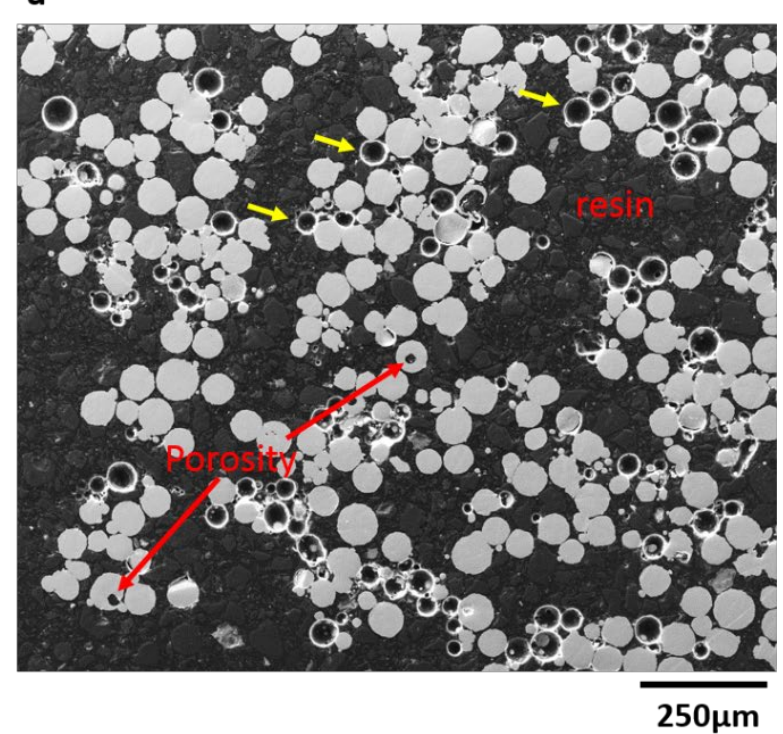

b

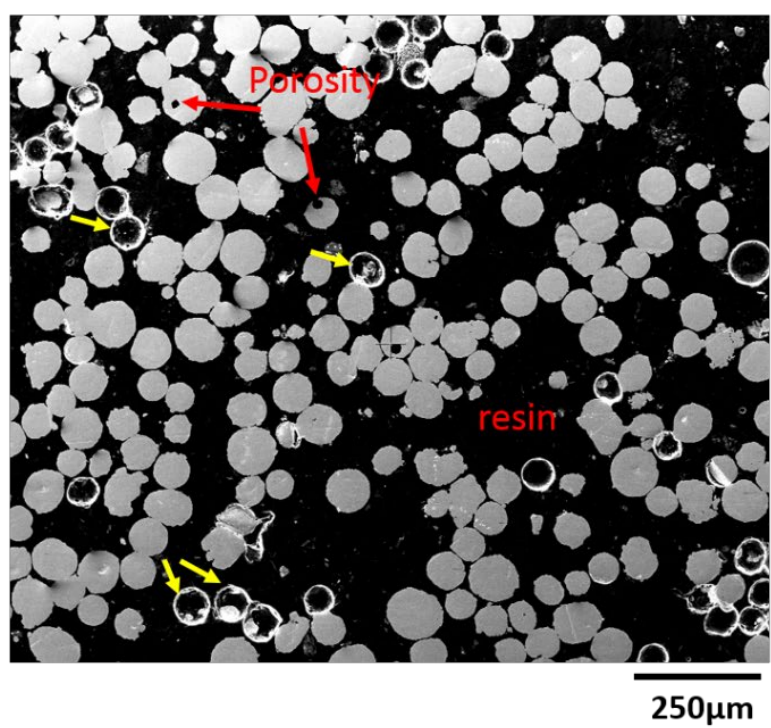

Extended Data Figure 8: SEM image of the cross section of a titanium powder and $\mathbf{b}$ copper powder. The powders are in spherical shape with a diameter between $50 \mu \mathrm{m}$ and $100 \mu \mathrm{m}$ and porosity can be observed within some powder particles. The yellow arrows indicate examples where powder particles fell out of the resin during the polishing process.

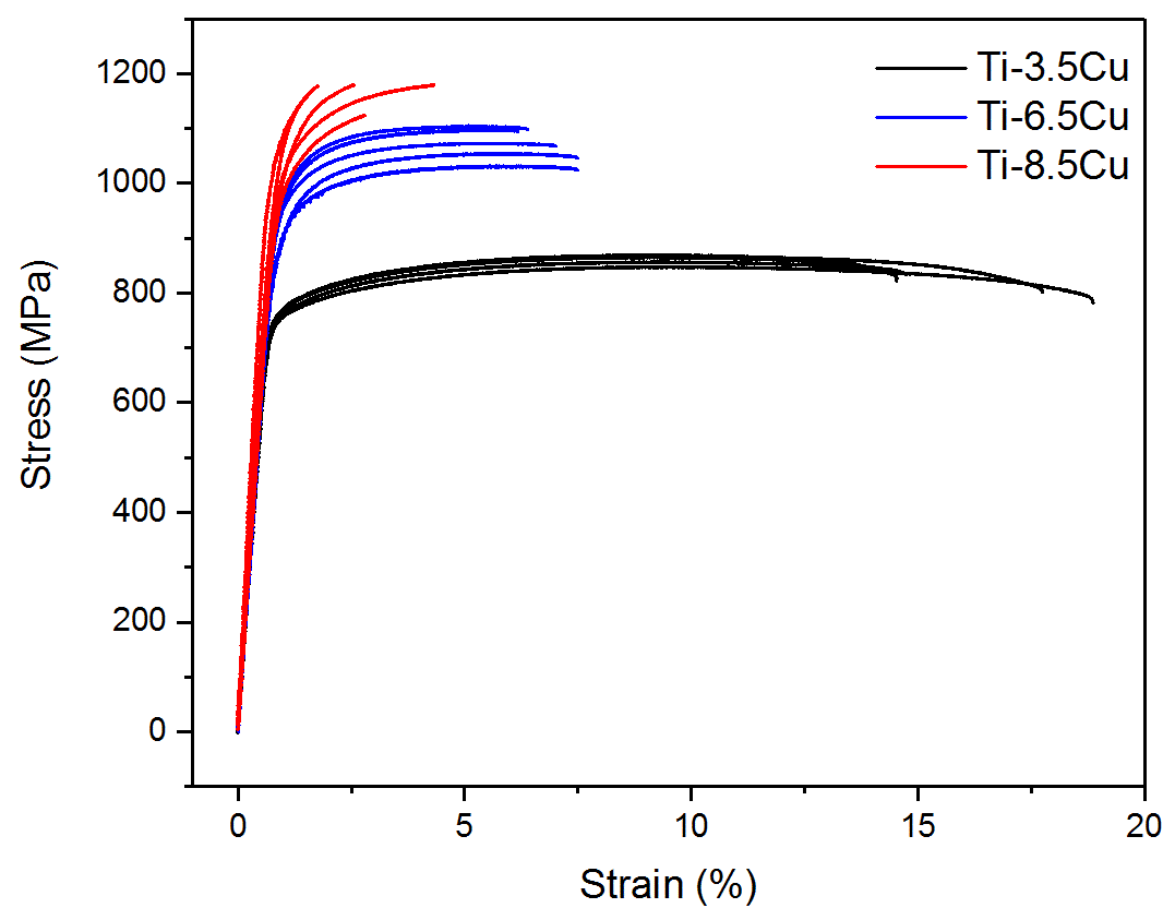


Extended Data Figure 9: Engineering stress/strain curves of the 3D-printed materials tested in this study, indicating good repeatability.

Extended Data Table 1: Volume fraction of eutectoid lamellae in the as-printed alloys.

\begin{tabular}{ll}
\hline Alloy & Eutectoid lamellae (\%) \\
\hline Ti-3.5Cu & 0 \\
Ti-6.5Cu & $53 \pm 7$ \\
Ti-8.5Cu & $92 \pm 4$ \\
\hline
\end{tabular}

Extended Data Table 2: Measured chemical compositions (wt.\%) of the as-printed alloys.

\begin{tabular}{lllll}
\hline $\begin{array}{l}\text { Nominal } \\
\text { Composition }\end{array}$ & $\mathrm{Ti}$ & $\mathrm{Cu}$ & $\mathrm{N}$ & $\mathrm{O}$ \\
\hline Ti-3.5Cu & Bal. & 3.20 & 0.01 & 0.22 \\
Ti-6.5Cu & Bal. & 6.33 & 0.02 & 0.23 \\
Ti-8.5Cu & Bal. & 8.36 & 0.02 & 0.21 \\
\hline
\end{tabular}

